\title{
Comparison of Laparoscopic and Open Emergency Surgery for Colorectal Perforation: A Retrospective Study
}

Kensuke Kudou ( $\nabla$ k.k.vermillion0920@gmail.com )

National Kyushu Medical Center

Tetsuya Kusumoto

National Kyushu Medical Center

Sho Nambara

National Kyushu Medical Center

Yasuo Tsuda

National Kyushu Medical Center

Eiji Kusumoto

National Kyushu Medical Center

Rintaro Yoshida

National Kyushu Medical Center

Yoshihisa Sakaguchi

National Kyushu Medical Center

Koji Ikejiri

National Kyushu Medical Center

\section{Research Article}

Keywords: colorectal perforation, emergency treatment, laparoscopic surgery, open surgical procedure, retrospective studies

Posted Date: November 11th, 2021

DOI: https://doi.org/10.21203/rs.3.rs-1058924/v1

License: (c) (i) This work is licensed under a Creative Commons Attribution 4.0 International License.

Read Full License 


\section{Abstract \\ Background}

This study aimed to clarify the safety and efficacy of laparoscopic surgery for colorectal perforation by comparing the clinical outcomes between laparoscopic and open emergency surgery for colorectal perforation.

\section{Methods}

We retrospectively reviewed the data of 100 patients who underwent surgery for colorectal perforation. The patients were categorized into two groups: the open group included patients who underwent laparotomy, and the laparoscopic group included those who underwent laparoscopic surgery. Clinical and operative characteristics and postoperative outcomes were evaluated.

\section{Results}

The open and laparoscopic groups included 58 and 42 patients, respectively. More than half of the patients in both groups developed perforation in the sigmoid colon (open, 55.2\%; laparoscopic, 59.5\%). The most common cause of perforation was diverticulum, followed by colorectal cancer. The mean intraoperative blood loss tended to be lower in the laparoscopic group than in the open group $(78.8 \mathrm{~mL}$ versus $160.1 \mathrm{~mL} ; P=0.0756)$. Hospital stay tended to be shorter in the laparoscopic group than in the open group (42.5 versus 55.7 days; $P=0.0965$ ). There were no significant differences in either the short- or long-term outcomes between the two groups. Univariate and multivariate analyses showed that the choice of surgical approach (open versus laparoscopic) did not affect overall survival in patients with colorectal perforation.

\section{Conclusions}

The laparoscopic approach for colorectal perforation in an emergency setting is a safe procedure compared with the open approach. The laparoscopic approach was associated with a decrease in intraoperative blood loss and a shorter length of hospital stay.

\section{Background}

In recent years, the usefulness and safety of laparoscopic surgery have been demonstrated in various abdominal surgical procedures, such as cholecystectomy, gastrectomy, and colectomy [1-6]. Regarding colorectal diseases, several studies have compared open and laparoscopic surgery under various conditions, such as total colectomy for acute colitis, surgery for colorectal cancers, and colectomy for inflammatory bowel diseases [5-11]. These studies suggest that the advantages of laparoscopic surgery 
include earlier recovery of bowel function, a lower incidence rate of postoperative complications, reduced pain scores, decreased estimated blood loss, and shorter hospital stay [6-9]. However, there are few studies on the efficacy of laparoscopic surgery in an emergency setting. A previous comparative study that examined the laparoscopic approach for emergency colorectal diseases was designed for patients with complicated diverticular disease [12], and another study targeted patients who underwent colectomy regardless of the primary diagnosis [13]. However, data are limited, and the role of the laparoscopic approach under emergency conditions remains controversial. Furthermore, the studies included patients with various conditions, such as colorectal obstruction, hemorrhage, fistula, and perforation [12, 13].

Therefore, this study focused on colorectal perforation, which can lead to high morbidity and mortality and often causes generalized peritonitis and septic shock. We aimed to clarify the safety and efficacy of laparoscopic surgery for colorectal perforation by comparing the clinical outcomes between laparoscopic and open emergency surgery for colorectal perforation.

\section{Methods}

\section{Patients}

In this retrospective cohort study, we reviewed the data of 372 patients who underwent emergency surgery for abdominal perforation peritonitis at our single institute between August 2010 and December 2019. One hundred patients who underwent open or laparoscopic surgery who were diagnosed with colorectal perforation were eligible for analysis. A total of 272 patients diagnosed with upper gastrointestinal perforation, perforation of the jejunum and ileum, perforation of the appendix, or postoperative anastomotic leakage were excluded. Patients were categorized into the open and laparoscopic groups according to the surgical approach used. Cases in which the initial laparoscopic approach was converted to the open laparotomy approach, according to intraoperative judgment, were included in the open group.

Moreover, 100 patients were categorized into the cancer group and non-cancer group based on the presence of cancer lesions at the time of perforation. In each group, the abovementioned analyses were performed.

Permission to perform this study was provided by the Institutional Review Board of the National Kyushu Medical Center (20C033). All procedures followed were in accordance with the ethical standards of the responsible committee on human experimentation (institutional and national) and with the Helsinki Declaration of 1964 and later versions. Informed consent to be included in the study or equivalent was obtained from all patients.

\section{Statistical analyses}

Differences in characteristics between the groups were evaluated using Fisher's exact test or an unpaired $t$-test. Survival curves were plotted according to the Kaplan-Meier method, and differences were analyzed 
using a log-rank test. Univariate and multivariate analyses were performed using a Cox proportional hazards model to identify independent prognostic factors. All $P$-values were two-sided, and $P$-value $<0.05$ was considered statistically significant. All analyses were performed using JMP PRO 11 software (SAS Institute Inc., https://www.jmp.com/ja_.jp/home.html).

\section{Results}

\section{Patient characteristics}

Patients were categorized into two groups (58 patients in the open group and 42 in the laparoscopic group) according to the surgical approach used. Baseline demographic and clinical features of patients in the open and laparoscopic groups are summarized in Table 1. There were no significant differences in age, sex, location, and causes of perforation between the two groups. More than half of the patients in both groups developed perforation in the sigmoid colon (open, 55.2\%; laparoscopic, 59.5\%). The incidence of rectal perforation was higher in the laparoscopic group than in the open group $(23.8 \%$ versus $15.5 \%$ ). Diverticulum was the most frequent cause of perforation, with $29.3 \%$ in the open group and $28.6 \%$ in the laparoscopic group, followed by colorectal cancer, with $27.6 \%$ and $23.8 \%$ in the open and laparoscopic groups, respectively. 
Table 1

Baseline demographic and clinical features of the open and laparoscopic groups

\begin{tabular}{|c|c|c|c|c|}
\hline WBC ( $(\mu l)$ & $\begin{array}{l}\text { Mean } \\
\text { (range) }\end{array}$ & $\begin{array}{l}8815 \pm 901 \\
(1300- \\
33200)\end{array}$ & $\begin{array}{l}9542 \pm 803 \\
(2000-22000)\end{array}$ & 0.5652 \\
\hline Factor & & $\begin{array}{l}\text { Open } \\
\text { group } \\
(n=58) \\
n(\%)\end{array}$ & $\begin{array}{l}\text { Laparoscopic group } \\
(n=42) \\
n(\%)\end{array}$ & $P$-value \\
\hline Sex & $\begin{array}{l}\text { Male } \\
\text { Female }\end{array}$ & $\begin{array}{l}29(50.0) \\
29(50.0)\end{array}$ & $\begin{array}{l}20(47.6) \\
22(52.4)\end{array}$ & 0.8418 \\
\hline Age, years & $\begin{array}{l}\text { Mean } \\
\text { (range) }\end{array}$ & $\begin{array}{l}71.7 \pm 1.5 \\
(41-91)\end{array}$ & $\begin{array}{l}72.1 \pm 2.1 \\
(26-95)\end{array}$ & 0.8766 \\
\hline Location & $\begin{array}{l}\text { C } \\
\text { A } \\
T \\
\text { D } \\
S \\
R\end{array}$ & $\begin{array}{l}4(6.9) \\
4(6.9) \\
5(8.6) \\
4(6.9) \\
32(55.2) \\
9(15.5)\end{array}$ & $\begin{array}{l}1(2.4) \\
2(4.8) \\
3(7.1) \\
1(2.4) \\
25(59.5) \\
10(23.8)\end{array}$ & \\
\hline $\begin{array}{l}\text { Side of the perforation } \\
\text { site }\end{array}$ & $\begin{array}{l}\text { Right } \\
\text { Left }\end{array}$ & $\begin{array}{l}13(22.4) \\
45(77.6)\end{array}$ & $\begin{array}{l}6(14.3) \\
36(85.7)\end{array}$ & 0.4393 \\
\hline $\mathrm{CRP}(\mathrm{mg} / \mathrm{dl})$ & $\begin{array}{l}\text { Mean } \\
\text { (range) }\end{array}$ & $\begin{array}{l}14.2 \pm 1.7 \\
(0.07-47.17)\end{array}$ & $\begin{array}{l}11.5 \pm 1.8 \\
(0.05-40.0)\end{array}$ & 0.2872 \\
\hline Albumin $(\mathrm{g} / \mathrm{dl})$ & $\begin{array}{l}\text { Mean } \\
\text { (range) }\end{array}$ & $\begin{array}{l}2.7 \pm 0.1 \\
(1.5-3.9)\end{array}$ & $\begin{array}{l}2.9 \pm 0.1 \\
(1.3-4.5)\end{array}$ & 0.2479 \\
\hline
\end{tabular}

Data are presented as the number (\%) unless otherwise stated. C, Cecum; A, Ascending colon; T, transverse colon; D, descending colon; S, sigmoid colon; R, rectum; WBC, white blood cell; CRP, Creactive protein; ESD, endoscopic submucosal dissection; EMR, endoscopic mucosal resection. 


\begin{tabular}{|c|c|c|c|c|}
\hline WBC ( $\mu l)$ & $\begin{array}{l}\text { Mean } \\
\text { (range) }\end{array}$ & $\begin{array}{l}8815 \pm 901 \\
(1300- \\
33200)\end{array}$ & $\begin{array}{l}9542 \pm 803 \\
(2000-22000)\end{array}$ & 0.5652 \\
\hline \multirow[t]{7}{*}{ Perforation causes } & Diverticulum & $17(29.3)$ & $12(28.6)$ & \\
\hline & Cancer & $16(27.6)$ & $10(23.8)$ & \\
\hline & \multirow{2}{*}{$\begin{array}{l}\text { Post-ESD or } \\
\text { EMR }\end{array}$} & $4(6.9)$ & $2(4.8)$ & \\
\hline & & $2(3.5)$ & $2(4.8)$ & \\
\hline & Steroid & $0(0.0)$ & $2(4.8)$ & \\
\hline & Fecal & $11(19.0)$ & 5 (11.9) & \\
\hline & \multicolumn{2}{|l|}{ Unknown } & $9(21.4)$ & \\
\hline $\begin{array}{l}\text { Data are presented } \\
\text { transverse colon; } D \\
\text { reactive protein; } E S\end{array}$ & $\begin{array}{l}\text { umber }(\%) \text { un } \\
\text { ding colon; S, } \\
\text { copic submu }\end{array}$ & $\begin{array}{l}\text { therwise st } \\
\text { oid colon; } \mathrm{R} \\
\text { dissection; }\end{array}$ & $\begin{array}{l}\text { C, Cecum; A, A } \\
\text { um; WBC, white } \\
\text {, endoscopic m }\end{array}$ & $\begin{array}{l}\mathrm{n} ; \mathrm{T} \\
\mathrm{PP}, \mathrm{C}- \\
\text { on. }\end{array}$ \\
\hline
\end{tabular}

\section{Operative outcomes}

Operative outcomes were compared between the open and laparoscopic groups and are summarized in Table 2. There were no significant differences in the mean operative times (open, 145 min versus laparoscopic, $148 \mathrm{~min} ; P=0.8148$ ) and occurrence of postoperative complications (open, $56.9 \%$ versus laparoscopic, $45.2 \% ; P=0.3117$ ) between the two groups. Intraoperative blood loss was $78.8 \mathrm{~mL}$ and $160.1 \mathrm{~mL}(P=0.0756)$ and hospital stay was 42.5 and 55.7 days $(P=0.0965)$ in the laparoscopic and open groups, respectively. Regarding postoperative complications, the occurrence of surgical site infection (12.1\% versus $2.4 \%, P=0.1338)$ and abdominal abscess $(12.1 \%$ versus $7.1 \%, P=0.5131)$ was higher in the open group than in the laparoscopic group; however, the difference was not significant. Regarding prognosis, there were no significant differences in mortality within 30 days after surgery, hospital mortality, and median survival time (MST) between the two groups (Table 2). 
Table 2

Comparison of operative outcomes between the open and laparoscopic groups

\begin{tabular}{|c|c|c|c|c|}
\hline \multirow{2}{*}{$\begin{array}{l}\text { Intra-abdominal } \\
\text { abscess }\end{array}$} & No & $51(87.9)$ & $39(92.9)$ & \multirow[t]{2}{*}{0.5131} \\
\hline & Yes & $7(12.1)$ & $3(7.1)$ & \\
\hline \multirow[t]{4}{*}{ Factor } & & Open & Laparoscopic & $P$ \\
\hline & & group & & \\
\hline & & $(n=58)$ & $(n=42)$ & \\
\hline & & n (\%) & n (\%) & \\
\hline \multirow[t]{5}{*}{ Surgical procedure } & Stoma & $23(39.7)$ & $25(59.5)$ & \\
\hline & Resection+anastomosis & $5(8.6)$ & $1(2.4)$ & \\
\hline & Resection+anastomosis+stoma & $3(5.2)$ & $1(2.4)$ & \\
\hline & Resection+stoma & $26(44.8)$ & $14(33.3)$ & \\
\hline & Others & $1(1.7)$ & $1(2.4)$ & \\
\hline \multirow[t]{2}{*}{ Operative time (min) } & Mean & $145.5 \pm 6.4$ & $148.0 \pm 9.3$ & 0.8148 \\
\hline & (range) & $(35-267)$ & $(48-298)$ & \\
\hline \multirow{2}{*}{$\begin{array}{l}\text { Intraoperative blood } \\
\text { loss (ml) }\end{array}$} & Mean & $160.1 \pm 33.8$ & $78.8 \pm 25.4$ & 0.0756 \\
\hline & (range) & $(0-1210)$ & $(0-866)$ & \\
\hline \multirow{2}{*}{$\begin{array}{l}\text { Postoperative } \\
\text { complication }\end{array}$} & No & $25(43.1)$ & $23(54.8)$ & 0.3117 \\
\hline & Yes & $33(56.9)$ & $19(45.2)$ & \\
\hline \multirow[t]{2}{*}{ Surgical site infection } & No & $51(87.9)$ & $41(97.6)$ & 0.1338 \\
\hline & Yes & $7(12.1)$ & $1(2.4)$ & \\
\hline \multirow[t]{2}{*}{ Ileus } & No & $55(94.8)$ & $36(85.7)$ & 0.1603 \\
\hline & Yes & $3(5.2)$ & $6(14.3)$ & \\
\hline \multirow[t]{2}{*}{$C D$ grade $\geq 3 a$} & $<3 a$ & $44(75.9)$ & $33(78.6)$ & 0.8133 \\
\hline & $\geq 3 a$ & $14(24.1)$ & $9(21.4)$ & \\
\hline \multirow[t]{2}{*}{ Hospital stay (days) } & Mean & $55.7 \pm 5.5$ & $42.5 \pm 5.2$ & 0.0965 \\
\hline & (range) & $(1-232)$ & $(7-143)$ & \\
\hline \multirow[t]{2}{*}{ Prognosis } & Survival & $32(55.2)$ & $21(50.0)$ & 0.6864 \\
\hline & Death & $26(44.8)$ & $21(50.0)$ & \\
\hline
\end{tabular}

Data are presented as the number (\%) unless otherwise stated. CD, Clavien-Dindo classification. 


\begin{tabular}{|lllll|}
\hline $\begin{array}{l}\text { Intra-abdominal } \\
\text { abscess }\end{array}$ & No & $\mathbf{5 1 ( 8 7 . 9 )}$ & $\mathbf{3 9 ( 9 2 . 9 )}$ & $\mathbf{0 . 5 1 3 1}$ \\
& Yes & $\mathbf{7 ( 1 2 . 1 )}$ & $\mathbf{3}(\mathbf{7 . 1})$ & \\
\hline $\begin{array}{l}\text { Mortality within } 30 \text { days } \\
\text { after surgery }\end{array}$ & Survival & $51(87.9)$ & $37(88.1)$ & 1.0000 \\
& Death & $7(12.1)$ & $5(11.9)$ & \\
\hline Hospital mortality & Survival & $46(79.3)$ & $36(85.7)$ & 0.4440 \\
& Death & $12(20.7)$ & $6(14.3)$ & \\
\hline $\begin{array}{l}\text { Median survival time } \\
\text { (days) }\end{array}$ & & 1313 & 653 & 0.5630 \\
\hline Data are presented as the number (\%) unless otherwise stated. CD, Clavien-Dindo classification. \\
\hline
\end{tabular}

\section{Postoperative survival}

The Kaplan-Meier method was used to analyze the overall survival (OS) and to compare the postoperative prognosis between the open and laparoscopic groups (Fig. 1). Although the MSTs of the open and laparoscopic groups were 1313 and 653 days, respectively, 1 -year OS rates were $62.0 \%$ and $69.2 \%$, respectively. There were no significant differences in 1-year OS rates between the two groups $(P=0.5630)$. Comparing the prognosis according to the cause of perforation, patients with cancer at surgery had a significantly worse prognosis than patients with other diseases (1-year OS, $38.0 \%$ versus $73.9 \%, \mathrm{MST}, 205$ versus 1590 days; $P=0.0002$ ) (Fig. 2). The survival data between open and laparoscopic surgery were compared for patients with cancer and those with other diseases. There were no significant differences in 1-year OS rates between the two groups (Fig. 3).

\section{Predictive factors for postoperative survival}

Univariate and multivariate analyses showed that the occurrence of postoperative complications ( $P=0.0075$ and 0.0141 , respectively) and cancer (versus other diseases) $(P=0.0006$ and 0.0011 , respectively) were independent predictive factors for poorer 1-year OS rates in patients with colorectal perforation. The surgical approach taken (open versus laparoscopic) was not associated with differences in 1-year OS rates in patients with colorectal perforation in both univariate and multivariate analyses (Table 3). 
Table 3

Univariate and multivariate analyses for overall survival

\begin{tabular}{|lllll|}
\hline Factor & Univariate analysis & \multicolumn{3}{l|}{ Multivariate analysis } \\
\hline & HR $(95 \% \mathrm{Cl})$ & $P$-value & HR $(95 \% \mathrm{Cl})$ & $P$-value \\
\hline Female (vs. Male) & $1.016(0.570-1.824)$ & 0.9561 & $1.036(0.561-1.921)$ & 0.9110 \\
\hline Age $<75$ y (vs. $\geq 75 \mathrm{y})$ & $1.431(0.800-2.553)$ & 0.2245 & $1.360(0.752-2.453)$ & 0.3062 \\
\hline $\begin{array}{l}\text { Right side of the colon } \\
\text { (vs. left side) }\end{array}$ & $1.112(0.522-2.154)$ & 0.7693 & $1.189(0.543-2.392)$ & 0.6476 \\
\hline Postoperative complication & $2.225(1.236-4.116)$ & 0.0075 & $2.131(1.164-3.999)$ & 0.0141 \\
\hline Cancer (vs. other diseases) & $2.981(1.625-5.353)$ & 0.0006 & $2.860(1.540-5.223)$ & 0.0011 \\
\hline Laparoscopic (vs. open) & $1.187(0.658-2.118)$ & 0.5649 & $1.270(0.696-2.291)$ & 0.4312 \\
\hline Cl, confidence interval; HR, hazard ratio & & & \\
\hline
\end{tabular}

\section{Discussion}

This study demonstrated that laparoscopic surgery for colorectal perforation tended to be associated with a reduced amount of intraoperative blood loss and a shorter length of hospital stay. The operative outcomes indicated that the laparoscopic approach could be performed safely in emergency surgery for colorectal perforation with accurate decision-making regarding the indications.

Several studies have compared outcomes between open and laparoscopic approaches for various diseases and conditions [1-13]. Siletz et al. have suggested that laparoscopic surgery is associated with reduced complication rates, shorter operative times, shorter lengths of stay, and lower rates of discharge to skilled nursing facilities for various abdominal conditions, such as gastric perforation, small bowel disease, and ventral hernia [14]. Despite this, Cocorullo et al. have indicated that, for the elderly population, there are no differences in operation times, morbidity rates, and mortality rates between patients undergoing open and laparoscopic approaches for abdominal emergencies, including gastroduodenal ulcer, small bowel disease, colonic acute disease, cholecystitis, and appendicitis [15]. Thus, these studies demonstrate that the laparoscopic approach can be safely performed even for emergency abdominal surgery $[14,15]$.

Focusing on the previous reports related to surgery for colorectal disease in the emergency setting, Turley et al. compared laparoscopic and open Hartmann procedures for the emergency treatment of diverticulitis and demonstrated that the laparoscopic approach results in fewer overall complications and a shorter mean length of hospitalization; however, it does not decrease morbidity or mortality [16]. Koh et al. compared the outcomes of laparoscopic colectomies with those of open colectomies under emergency 
conditions, such as colorectal bleeding, obstruction, and perforation, and demonstrated that the operative times in laparoscopic colectomies were longer than those in open colectomies, while the duration of hospitalization and postoperative morbidity between the two groups were similar [13]. Letarte et al. compared the perioperative outcomes of laparoscopic colon resection and open colon resection for the treatment of complicated diverticular disease in the emergency setting, and they suggested that laparoscopic surgery was associated with decreased morbidity, intraoperative blood loss, time to oral intake, and length of hospital stay, while the mean operative time was longer than that of the open approach [12].

The above studies targeted colorectal disease with indications for emergency surgery, and they included various conditions, such as perforation, hemorrhage, and obstruction. The differences among these conditions are important and may substantially affect surgical procedures or perioperative outcomes. Notably, colorectal perforation has an extremely poor prognosis due to generalized peritonitis and sepsis, and it often requires extensive drainage. Therefore, this study only focused on colorectal perforation. Our findings on intraoperative blood loss and hospital stay were similar to those reported previously. Most previous studies have demonstrated that the laparoscopic approach requires longer operative times [12, 13], whereas our study showed that the mean operative times were not different between the open and laparoscopic groups. This finding might be related to the patients in our study, who had all received a diagnosis of colorectal perforation and who were usually in poor general condition and required urgent surgery. Consequently, decisions to convert to open surgery for patients in whom it was difficult to complete laparoscopic surgery may have been made faster than for those with other diseases.

This study focused on the causes of colorectal perforation, i.e., malignant or benign diseases, because they might affect the prognosis. Indeed, there were significant differences in the prognoses of patients with and without cancer. Moreover, in patients with cancer, progression of the primary cancer may be associated with their prognoses. In this study, both the cancer and other disease groups demonstrated no significant differences in 1-year OS rates between the open and laparoscopic approaches.

This study had a few limitations. A main limitation of our study was selection bias. The surgical procedure chosen, namely, an open or a laparoscopic approach, was dependent on each surgeon's decision. Consequently, surgeons who are proficient in laparoscopic surgery may tend to select the laparoscopic approach for wider indications, and choices of the surgeons may affect surgical and postoperative outcomes. In addition, this was a single-institution retrospective study that included a small sample size. Patients in this study were diagnosed with colorectal perforation and underwent emergency surgery; therefore, it was impossible to avoid selection bias or to design a prospective study. A comparison of the findings obtained from retrospective studies from various institutes would be meaningful. The findings from the current study may provide useful information regarding the clinical value of the laparoscopic approach for colorectal perforation in an emergency setting.

\section{Conclusions}


The laparoscopic approach for colorectal perforation in an emergency setting is a safe procedure when conducted after careful patient selection, and it may decrease intraoperative blood loss and shorten the length of hospital stay.

\section{Abbreviations}

OS, overall survival

MST, median survival time

\section{Declarations}

Ethics approval and consent to participate. Permission to perform this study was provided by the Institutional Review Board of the National Kyushu Medical Center (20C033). Informed consent to be included in the study or equivalent was obtained from all patients. All procedures followed were in accordance with the ethical standards of the responsible committee on human experimentation (institutional and national) and with the Helsinki Declaration of 1964 and later versions. Informed consent to be included in the study or equivalent was obtained from all patients.

\section{Consent for publication}

Not Applicable

Availability of data and material. The data are available upon reasonable request by contacting the corresponding author.

Conflicts of interest/Competing interests. Dr. Kensuke Kudou was supported by grants from the Kaibara Morikazu Medical Science Promotion Foundation in 2019, the Uehara Memorial Foundation in 2020, Grant of The Clinical Research Promotion Foundation in 2020 and Fukuoka Public Health Promotion Organization Cancer Research Fund in 2021. Drs. Tetsuya Kusumoto, Yuho Ebata, Sho Nambara, Yasuo Tsuda, Eiji Kusumoto, Rintaro Yoshida, Yoshihisa Sakaguchi, and Koji Ikejiri have no conflicts of interest or financial ties to disclose.

Funding. Dr. Kensuke Kudou was supported by grants from the Kaibara Morikazu Medical Science Promotion Foundation in 2019, the Uehara Memorial Foundation in 2020, Grant of The Clinical Research Promotion Foundation in 2020 and Fukuoka Public Health Promotion Organization Cancer Research Fund in 2021. The funding bodies played no role in the design of the study and collection, analysis, and interpretation of data and in writing the manuscript.

\section{Authors' contributions.}

K.K. designed the study. K.K., E.K., S.N., Y.T., and R.Y. acquired the data. 
Analysis and interpretation of data: K.K., E.K., and Y.S. analyzed the data. K.K. performed statistical analyses. K.K. and T.K. drafted the article. T.K., and Y.S. revised the article critically for important intellectual content. T.K., Y.S., and K.I. approved the final version of manuscript. All authors have read and approved the manuscript.

Acknowledgments. We thank the Kaibara Morikazu Medical Science Promotion Foundation and Fukuoka Public Health Promotion Organization Cancer Research Fund for financial support. We thank Editage (https://www.editage.jp/) for language editing.

\section{References}

1. Johansson M, Thune A, Nelvin L, Stiernstam M, Westman B, Lundell L. Randomized clinical trial of open versus laparoscopic cholecystectomy in the treatment of acute cholecystitis. Br J Surg. 2005;92(1):44-9.

2. Lee HJ, Hyung WJ, Yang HK, Han SU, Park YK, An JY, et al. Short-term outcomes of a multicenter randomized controlled trial comparing laparoscopic distal gastrectomy with D2 lymphadenectomy to open distal gastrectomy for locally advanced gastric cancer (KLASS-02-RCT). Ann Surg. 2019;270(6):983-91.

3. Huscher CG, Mingoli A, Sgarzini G, Sansonetti A, Di Paola M, Recher A, et al. Laparoscopic versus open subtotal gastrectomy for distal gastric cancer: five-year results of a randomized prospective trial. Ann Surg. 2005;241(2):232-7.

4. Kim SM, Youn HG, An JY, Choi YY, Noh SH, Oh SJ, et al. Comparison of open and laparoscopic gastrectomy in elderly patients. J Gastrointest Surg. 2018;22(5):785-91.

5. Gervaz P, Inan I, Perneger T, Schiffer E, Morel P. A prospective, randomized, single-blind comparison of laparoscopic versus open sigmoid colectomy for diverticulitis. Ann Surg. 2010;252(1):3-8.

6. Guillou PJ, Quirke P, Thorpe H, Walker J, Jayne DG, Smith AM, et al. Short-term endpoints of conventional versus laparoscopic-assisted surgery in patients with colorectal cancer (MRC CLASICC trial): multicentre, randomised controlled trial. Lancet. 2005;365:1718-26.

7. Hida K, Okamura R, Sakai Y, Konishi T, Akagi T, Yamaguchi T, et al. Open versus laparoscopic surgery for advanced low rectal cancer: a large, multicenter, propensity score matched cohort study in Japan. Ann Surg. 2018;268(2):318-24.

8. Veldkamp R, Kuhry E, Hop WC, Jeekel J, Kazemier G, Bonjer HJ, et al. Laparoscopic surgery versus open surgery for colon cancer: short-term outcomes of a randomised trial. Lancet Oncol. 2005;6:47784.

9. Marcello PW, Milsom JW, Wong SK, Brady K, Goormastic M, Fazio VW. Laparoscopic total colectomy for acute colitis: a case-control study. Dis Colon Rectum. 2001;44:1441-5.

10. Ng SS, Lee JF, Yiu RY, Li JC, Leung WW, Leung KL. Emergency laparoscopic-assisted versus open right hemicolectomy for obstructing right-sided colonic carcinoma: a comparative study of shortterm clinical outcomes. World J Surg. 2008;32:454-8. 
11. Qazi SM, Skovdal J, Munck LK, Bisgaard T. High morbidity after laparoscopic emergency colectomy for inflammatory bowel disease. Dan Med Bull. 2011;58:A4326.

12. Letarte F, Hallet J, Drolet S, Boulanger-Gobeil C, Bouchard A, Grégoire RC, et al. Laparoscopic versus open colonic resection for complicated diverticular disease in the emergency setting: a safe choice? A retrospective comparative cohort study. Am J Surg. 2015;209(6):992-8.

13. Koh FH, Tan KK, Tsang CB, Koh DC. Laparoscopic versus an open colectomy in an emergency setting: a case-controlled study. Ann Coloproctol. 2013;29(1):12-6.

14. Siletz A, Grotts J, Lewis C, Tillou A, Cryer HM, Cheaito A. Comparative analysis of laparoscopic and open approaches in emergency abdominal surgery. Am Surg. 2017;83(10):1089-94.

15. Cocorullo G, Falco N, Tutino R, Fontana T, Scerrino G, Salamone G, et al. Open versus laparoscopic approach in the treatment of abdominal emergencies in elderly population. G Chir. 2016;37(3):10812.

16. Turley RS, Barbas AS, Lidsky ME, Mantyh CR, Migaly J, Scarborough JE. Laparoscopic versus open Hartmann procedure for the emergency treatment of diverticulitis: a propensity-matched analysis. Dis Colon Rectum. 2013;56(1):72-82.

\section{Figures}


Figure 1
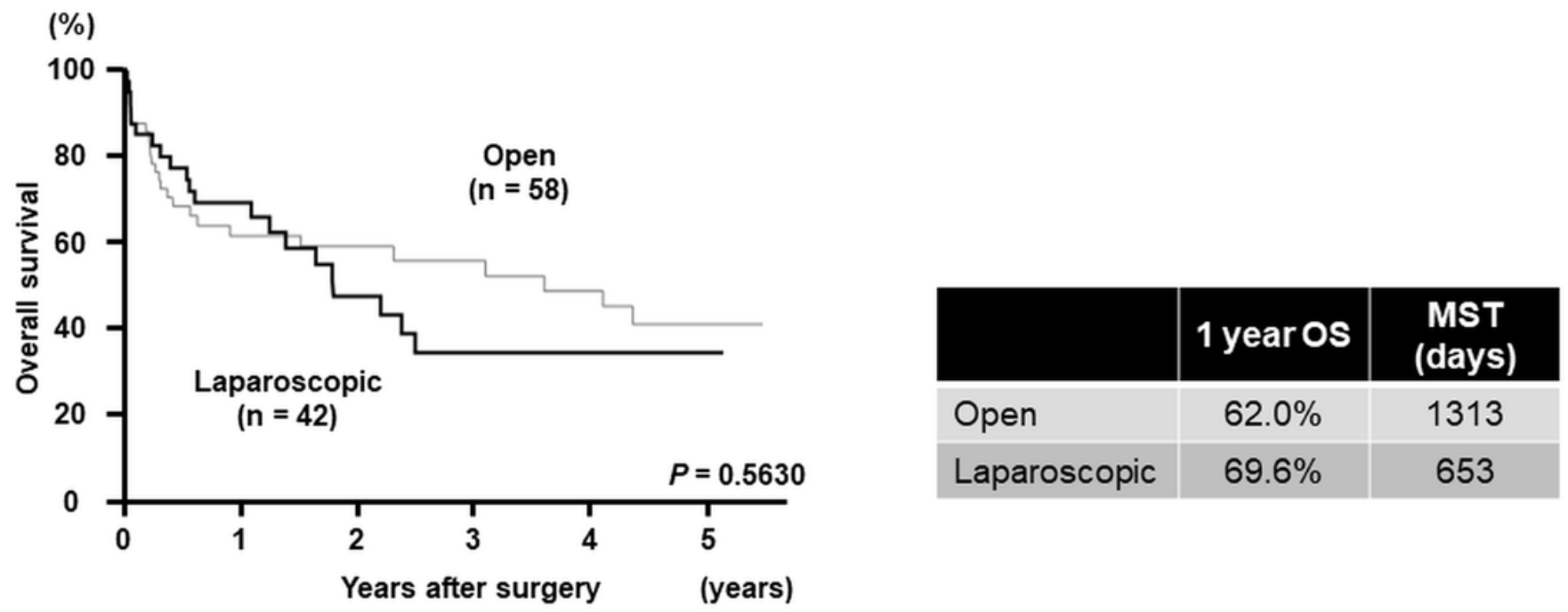

Number at risk

$\begin{array}{lllccl}\text { Open } & 26 & 22 & 16 & 14 & 7 \\ \text { Laparoscopic } & 21 & 11 & 6 & 3 & 1\end{array}$

\section{Figure 1}

Postoperative survival in patients with colorectal perforation based on surgical approach, including a comparison between the laparoscopic and open approaches. The 1-year overall survival rates and median survival time in the two groups are shown in the table. OS, overall survival; MST, median survival time 
Figure 2

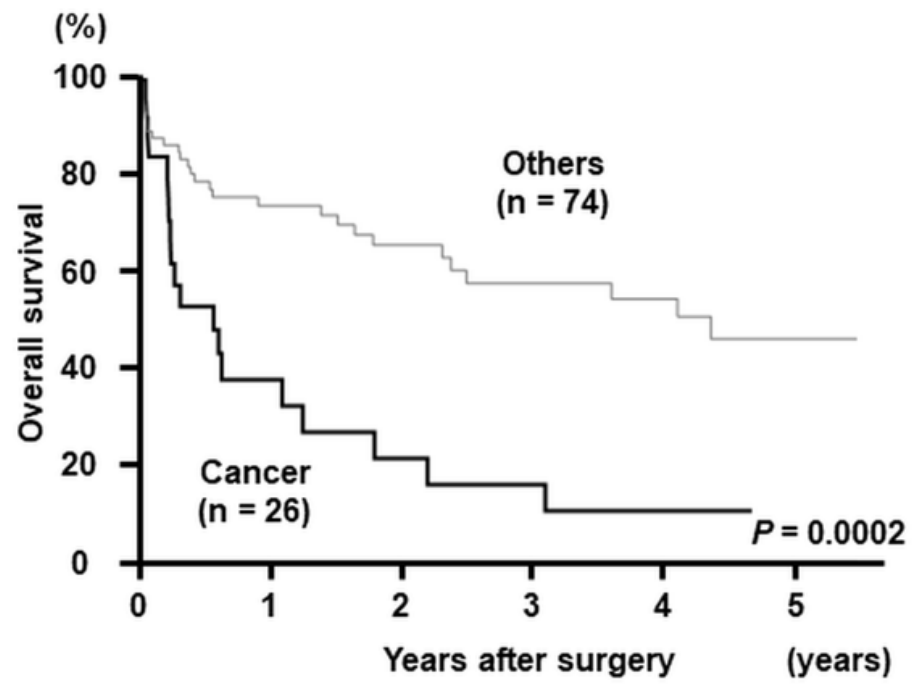

\begin{tabular}{|l|c|c|}
\hline & 1 year os & $\begin{array}{c}\text { MST } \\
\text { (days) }\end{array}$ \\
\hline Others & $73.9 \%$ & 1590 \\
\hline Cancer & $38.0 \%$ & 205 \\
\hline
\end{tabular}

Number at risk

$\begin{array}{lccccc}\text { Others } & 40 & 29 & 19 & 15 & 8 \\ \text { Cancer } & 7 & 4 & 3 & 2 & 0\end{array}$

\section{Figure 2}

Postoperative survival in patients with colorectal perforation based on the causes of the perforation, including a comparison between cancer and other diseases. The 1-year overall survival rates and median survival time in the two groups are shown in the table. OS, overall survival; MST, median survival time 
Figure 3
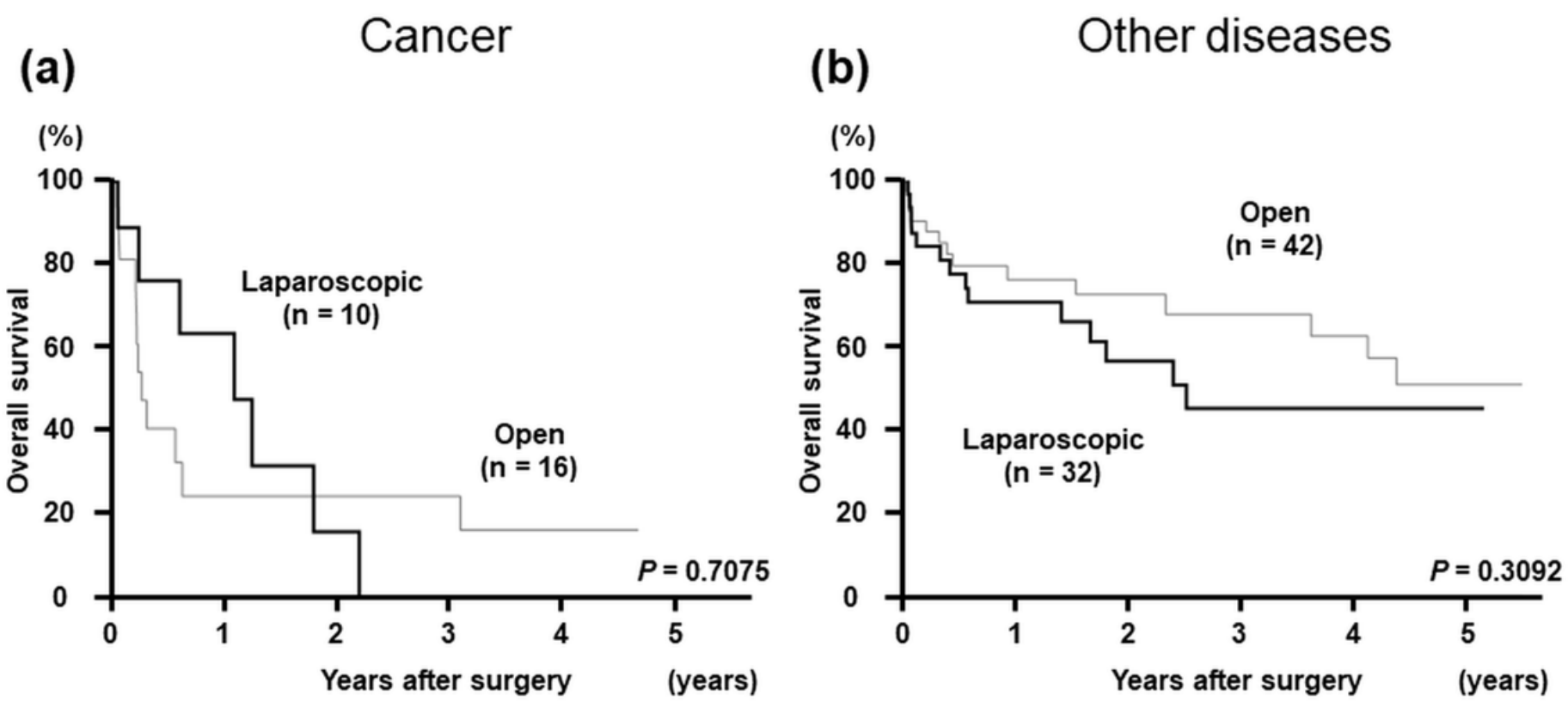

Number at risk

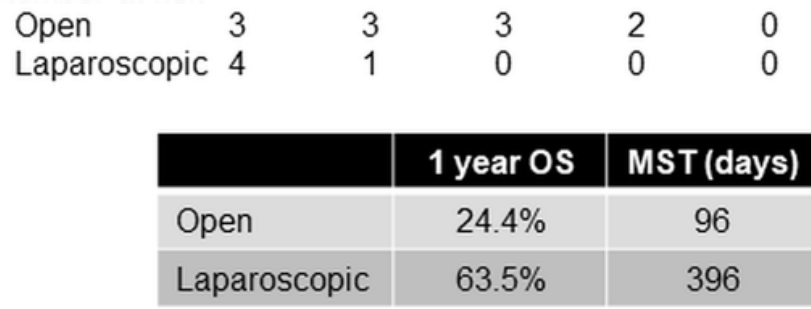

Number at risk

$\begin{array}{llllcl}\text { Open } & 23 & 19 & 13 & 12 & 7 \\ \text { Laparoscopic } & 17 & 10 & 6 & 3 & 1\end{array}$

\begin{tabular}{|l|c|c|}
\hline & 1 year OS & MST (days) \\
\hline Open & $76.4 \%$ & - \\
\hline Laparoscopic & $71.0 \%$ & 909 \\
\hline
\end{tabular}

\section{Figure 3}

Postoperative survival in patients with colorectal perforation based on surgical approach, including a comparison between the laparoscopic and open approaches after categorizing the patients into (a) cancer and (b) other disease groups according to the causes of perforation. The 1-year overall survival rates and median survival time in the two groups are shown in the table. OS, overall survival; MST, median survival time 